\title{
Maturation in vitro of oocytes recovered from prepubertal rhesus monkeys
}

\author{
K. G. Gould and C. E. Graham \\ Yerkes Regional Primate Research Center, Emory University, Atlanta, Georgia 30322, U.S.A.
}

As part of our efforts to increase the amount of material available for study of the fertilization of primate ova in vitro we are trying to utilize prepubertal females treated with gonadotrophins as oocyte donors. In the course of this work it was noted that oocytes recovered from follicles measuring 3-4 $\mathrm{mm}$ in diameter behaved in an unexpected manner.

Fifteen prepubertal rhesus monkeys weighing 3-4.5 $\mathrm{kg}$ were used. The precise ages of the females were not known, but menstruation had not been seen in any of the animals.

The females were given a daily i.m. injection of 500 i.u. PMSG (Gestyl: Organon) for 5 days before death. The ovaries were removed and oocytes recovered by puncture of the follicles under Ham's F10 medium.

The morphological normality and maturity of the oocytes was checked at $\times 160$ magnification before culture. Granulosa cells surrounding the oocytes were removed by gentle aspiration through a 25-gauge needle, and the oocytes washed in three changes of Ham's F10 medium. Oocytes were randomly distributed among various culture media (Table 1) and observed for evidence of maturation.

Table 1. The maturation of rhesus monkey oocytes in various media

\begin{tabular}{lcccc}
\hline Additions to basic medium of Ham's & $\begin{array}{c}\text { Total no. } \\
\text { of ova }\end{array}$ & $\begin{array}{c}\text { No. of ova } \\
\text { extruding } \\
\text { 'polar body' }\end{array}$ & $\begin{array}{c}\text { No. of ova with } \\
\text { metaphase II } \\
\text { confirmed by } \\
\text { lacmoid staining }\end{array}$ & $\begin{array}{c}\text { total ova } \\
\text { matured }\end{array}$ \\
\hline None & 35 & $1 \neq$ & 0 & 0 \\
Dibutyryl cyclic AMP $(8 \mu \mathrm{g} / \mathrm{ml})$ & 22 & 5 & $2 \S$ & 9 \\
Progesterone $(25 \mu \mathrm{g} / \mathrm{ml})$ & 20 & 6 & $4 *$ & 20 \\
Dibutyryl cyclic AMP + progesterone & 38 & 16 & $15 \dagger$ & 40 \\
\hline
\end{tabular}

* Significantly different from control; $\chi^{2}=7 \cdot 5, P<0.025$.

$\dagger$ Significantly different from control; $\chi^{2}=17 \cdot 38, P<0 \cdot 005$.

$\ddagger$ Oocyte with 'polar body' at start of culture.

$\S$ Both from a culture in which a few granulosa cells were inadvertently included; progesterone level was $<0.04 \mathrm{ng} / \mathrm{ml}$. Not significantly different from control; $\chi^{2}=3.04, P<0 \cdot 1$.

The oocytes were incubated for up to $48 \mathrm{hr}$ at $37^{\circ} \mathrm{C}$ in $0.5 \mathrm{ml}$ medium in 8-well dishes (Lab Tek) at a $\mathrm{pH}$ of 7.2 under moist $5 \% \mathrm{CO}_{2}$ in air at atmospheric pressure.

Oocytes were recorded as 'mature' if the first polar body was visible in the perivitelline space, chromatin was demonstrable within the polar body and a metaphase chromosome configuration could be demonstrated in the vitellus using lacmoid stain. Before incubation only one oocyte of 140 examined showed a structure resembling a polar body, and the 'maturity' of this oocyte was not confirmed using lacmoid stain. Approximately $25 \%$ of recovered oocytes possessed a distinct germinal vesicle.

No maturation was recorded after less than $22 \mathrm{hr}$ culture, indicating that the gonadotrophin stimulation in vivo did not itself induce maturation of the oocytes used in these experiments.

The results (Table 1) show that most oocytes matured when they were exposed simultaneously to progesterone and dibutyryl cyclic AMP (dbcAMP). Progesterone and dbcAMP together were more effective than either dbcAMP alone $(P<0.005)$ or control medium $(P<0.005)$. Progesterone alone was also significantly better than control medium, but not at the same level of confidence $(P<0.025)$; the higher percentage of matured oocytes under the combined influence of progesterone and dbcAMP

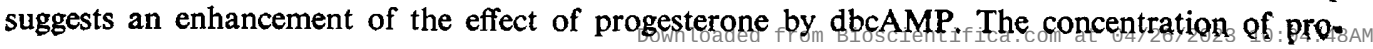


gesterone used was high $(25 \mu \mathrm{g} / \mathrm{ml})$, but might in fact result in physiological intracellular concentrations when the limited solubility of progesterone in aqueous solution and the possible reduction in transfer of progesterone across the zona pellucida in the absence of corona cells are considered.

A high proportion of the matured oocytes were morphologically abnormal, but there was no statistical correlation between composition of the culture medium and incidence of abnormality. Normal maturation of mammalian ova is stated to involve shrinkage of the vitellus, extrusion of the first polar body and establishment of a metaphase spindle tangential to the vitelline surface (Thibault, 1969). The oocytes in the present study demonstrated little vitelline shrinkage, with resultant compression of the polar body, and the metaphase spindle was frequently radial rather than tangential. This spindle abnormality has been recorded in rabbit oocytes matured in vitro, and was apparently compatible with subsequent fertilization in vitro (Thibault, 1972).

It is possible that progesterone and $\mathrm{LH}$, the latter replaced in these experiments by dbcAMP, initiate maturation of the oocyte and that other factors within the intact follicle are required to ensure normal maturation. There is a rise in progesterone output by ovarian tissues before ovulation (Johansson \& Wide, 1969; Kirton, Niswender, Midgely, Jaffe \& Forbes, 1970), and in the rabbit and cow oocyte maturation occurs more readily in the presence of progesterone or progesteronesecreting cells (Nicosia \& Mikhail, 1975).

Our results are not in agreement with other reports of maturation in rhesus monkey oocytes cultured without addition of hormones to the medium (Edwards, 1965; Suzuki \& Mastroianni, 1966). This discrepancy could arise from differences in methodology or source of material. Our experiments deliberately utilized oocytes from which the surrounding corona cells had been removed although it has been suggested that maturation of primate oocytes in Ham's F10 medium is reduced when corona cells are absent (Kennedy \& Donahue, 1969). However, of 20 oocytes cultured with corona cells in $\mathrm{F} 10+15 \%$ agamma bovine serum, only one showed evidence of maturation, and thus the failure to mature of naked oocytes cultured under our conditions cannot be ascribed to the absence of corona cells. It is also evident that the presence of corona cells did not compensate for the absence of progesterone from the medium.

The requirement for exposure in vitro to progesterone and dbcAMP for maturation of oocytes obtained from prepubertal PMSG-treated rhesus monkeys, but not from adults, suggests that oocytes recovered from adults require and receive hormonal priming in vivo, perhaps during the menstrual cycle(s) prior to that in which final maturation occurs. Such priming would be effectively absent from prepubertal animals.

This study re-emphasizes the need for careful definition of the source of material for analysis of the hormonal control of ovum maturation in vitro, and shows that the maturation of primate oocytes induced in vitro is not necessarily normal.

We thank Dr S. Adams, Centre for Disease Control, Atlanta, for help in obtaining the ovaries. The research was supported by NIH Fellowship F02-HD55, 742-01, Ford Foundation Grant No. 690-0645 A and NIH Grant No. RR00165.

\section{References}

EDWARDS, R.G. (1965) Maturation in vitro of mouse, sheep, cow, pig, rhesus monkey and human ovarian oocytes. Nature, Lond. 208, 349-351.

Johansson, E.D.B. \& Wide, L. (1969) Periovulatory levels of plasma progesterone and luteinizing hormone in women. Acta endocr., Copenh. 62, 82-88.

Kennedy, J.F. \& Donahue, R.P. (1969) Human oocytes: maturation in chemically defined media. Science, N.Y. 164, 1292-1293.

Kirton, K.T., Niswender, G.G., Midgely, A.R., JAFFe, R.B. \& Forbes, A.D. (1970) Serum LH and progesterone concentration during the menstrual cycle of the rhesus monkey. J. clin. Endocr. Metab. 30, 105-110. tissue culture: hormone production, ultrastructure and morphometry of early luteinization. Fert. Steril. 26, 427-448.

Thibaulr, C.G. (1969) In vitro fertilization of the mammalian egg. In Fertilization, Vol. II, pp. 405-435. Eds C. B. Metz \& A. Munroy. Academic Press, London.

Thibault, C.G. (1972) Final stages of mammalian oocyte maturation. In Oogenesis, pp. 397-412. Eds J. D. Biggers \& A. W. Schuetz. University Park Press, Baltimore.

Suzuki, S. \& MastrolanNI, L. (1966) Maturation of monkey ovarian follicular oocytes in vitro. Am. J. Obstet, Gynec. 96, 723-731.

Nicosia, S.V. \& MikhaIL, G. (1975) Cumuli oophori in Downloaded from Bioscientifica.com at 04/26/2023 10:04:48AM 